\title{
Burnout among Hospital Pharmacists: Prevalence, Self-Awareness, and Preventive Programs in Pharmacy School Curricula
}

\author{
Colby Weichel, Joan S Lee, and Justin Y Lee
}

Can J Hosp Pharm. 2021;74(4):309-16

DOI: 10.4212/cjhp.v74i4.3192

\begin{abstract}
Background: Clinician burnout is a work-related syndrome characterized by emotional exhaustion, depersonalization, and reduced personal accomplishment. It is associated with reduced quality of care, as well as the occurrence of medical errors and mental illness. Although burnout has been extensively studied in populations of physicians and nurses, there is limited research assessing burnout in pharmacists and their exposure to burnout-related education.
\end{abstract}

Objectives: To determine the prevalence of burnout and its associated risk factors among hospital pharmacists and to explore the status of preventive programs in pharmacy school curricula.

Methods: A cross-sectional online survey was conducted with hospital pharmacists working in the province of Ontario, Canada. Respondents completed the Maslach Burnout Inventory (MBI) and responded to questions about career characteristics and professional satisfaction. A multivariable regression analysis was used to determine factors independently associated with burnout. In addition, all pharmacy schools in Canada were surveyed electronically about their burnoutprevention curricula.

Results: Of 2465 hospital pharmacists in Ontario, 270 responded (11\% response rate). Most respondents were women (77\% [195/252]) and were working full-time (90\% [227/252]), with a substantial proportion working in the acute care setting (39\% [96/246]). The burnout rate was $61.1 \%$ (165/270; $95 \%$ confidence interval $55.5 \%-66.8 \%$ ). Factors independently associated with burnout were dissatisfaction with work-life balance (odds ratio [OR] 2.62, $p=0.005$ ) and feeling that contributions were unappreciated (OR 2.60, $p=0.019$ ). Of those whose MBI score indicated burnout, 23\% (36/158) were not aware of experiencing burnout. All 10 Canadian pharmacy schools responded to the survey, with $9(90 \%)$ reporting that they did not have burnout-prevention curricula; however, $8(80 \%)$ reported interest in incorporating such material.

Conclusions: The rate of burnout among hospital pharmacists in Ontario was high, and preventive action is needed. Opportunities exist to both improve pharmacists' resilience at the undergraduate level and reduce institutional stressors in the workplace.

Keywords: burnout, hospital, pharmacists, pharmacy education

\begin{abstract}
RÉSUMÉ
Contexte : L'épuisement professionnel du clinicien est un syndrome lié au travail qui se caractérise par une fatigue émotionnelle, une dépersonnalisation et l'amoindrissement des réalisations personnelles. II est associé à la réduction de la qualité des soins, à la survenance d'erreurs médicales et à la maladie mentale. Bien que ce sujet ait fait l'objet d'études approfondies dans les populations de médecins et d'infirmiers, les recherches qui se penchent sur l'épuisement des pharmaciens et la possibilité qui leur est offerte de bénéficier de formations relatives à l'épuisement sont limitées.
\end{abstract}

Objectifs : Déterminer la prévalence du surmenage professionnel et des facteurs de risque qui lui sont associés parmi les pharmaciens d'hôpitaux et examiner les programmes de prévention dans les formations en école de pharmacie.

Méthode : Une enquête transversale en ligne a été menée auprès des pharmaciens hospitaliers travaillant en Ontario, au Canada. Les répondants ont rempli le Maslach Burnout Inventory (MBI) [Evaluation du syndrome de l'épuisement professionnel de Maslach] et répondu à des questions portant sur les caractéristiques d'emploi et la satisfaction professionnelle. Une analyse de régression multivariable a permis de déterminer les facteurs indépendamment associés à l'épuisement. De plus, une enquête électronique portant sur le programme de prévention de l'épuisement a été menée dans toutes les écoles de pharmacie au Canada.

Résultats : Sur les 2465 pharmaciens d'hôpitaux en Ontario, 270 ont répondu (taux de réponse de $11 \%$ ). La plupart des répondants étaient des femmes (77 \% [195/252]) travaillant à temps plein (90 \% [227/252]); une part importante travaillait dans un environnement de soins aigus (39\% [96/246]). Le taux d'épuisement était de $61,1 \%$ (165/270, intervalle de confiance $95 \%$ $55,5 \%-66,8 \%)$. Les facteurs indépendamment associés à l'épuisement étaient I'insatisfaction liée à l'équilibre entre sa vie professionnelle et sa vie personnelle (rapport de cotes $[R C] 2,62, p=0,005$ ) et l'impression d'un manque d'appréciation de sa contribution ( $R C 2,60, p=0,019$ ). Parmi les personnes dont le score MBI indiquait un épuisement professionnel, 23 \% (36/158) ne savaient pas qu'elles en étaient victimes. Les dix écoles de pharmacie canadiennes ont répondu à l'enquête et neuf ( $90 \%$ ) ont rapporté ne pas avoir de programme axé sur la prévention de l'épuisement professionnel, cependant, huit $(80 \%)$ ont montré leur intérêt pour un tel programme.

Conclusions : Le taux d'épuisement professionnel parmi les pharmaciens d'hôpitaux en Ontario était élevé et des actions préventives sont nécessaires. Les possibilités existent pour améliorer la résilience des pharmaciens au niveau du premier cycle universitaire et réduire les facteurs de stress institutionnels sur le lieu de travail.

Mots-clés : épuisement, hôpital, pharmaciens, formation en pharmacie 


\section{INTRODUCTION}

Burnout has been described as a work-related syndrome characterized by 3 elements: emotional exhaustion, depersonalization, and reduced feelings of personal accomplishment. ${ }^{1}$ Among health care providers, this syndrome occurs when they begin to feel overwhelmed and frustrated by unforeseen circumstances, while attempting to have a positive impact on their patients' lives. ${ }^{1}$ The occurrence of burnout has a significant impact on the health care system, as it is known to be associated with reduced quality of care, as well as with medical errors and mental illness. ${ }^{2,3}$ Among physicians in the United States, burnout is estimated to cost the health care system US $\$ 4.6$ billion per year through reduced working hours and physician turnover. ${ }^{4}$ This amount is likely an underestimate, as it does not include the downstream effects and costs of burnout, such as medical errors, patient dissatisfaction, and increased malpractice lawsuits. ${ }^{4}$

Although burnout has been well characterized for physicians and nurses, study of burnout among pharmacists is still lacking. In 2016, a pilot survey of hospital pharmacists in the United States found a burnout rate of $61.2 \%$ that was largely driven by high emotional exhaustion. ${ }^{5}$ To our knowledge, there are no previous studies in a Canadian context, and the current level of burnout among Canadian hospital pharmacists is unknown. It is unclear whether a high level of burnout is a regional phenomenon or whether burnout is more universal across jurisdictions, with rates similar to the United States.

Numerous strategies are currently being used to prevent and treat burnout, including mindfulness-based interventions, psychotherapy, and didactic education. Several health professional student groups have demonstrated the success of burnout-prevention strategies at the student level. ${ }^{6-11}$ It is unknown whether pharmacy schools have implemented any courses or programs targeting the prevention of burnout in the workforce and if not, whether they would be interested in implementing such training.

To address these gaps, this study was undertaken to explore burnout in the Canadian pharmacy context. The primary objective was to determine the prevalence of burnout and its associated risk factors among hospital pharmacists in Ontario, which is the largest province in Canada (population 14.57 million in 2019). The secondary objective was to explore the current status of and interest in preventive programs in pharmacy school curricula.

\section{METHODS}

This study was based on 2 online surveys: a survey of Ontario hospital pharmacists and a survey of all 10 faculties and schools of pharmacy in Canada. The CHERRIES checklist was used to guide reporting of the methods and results of this study, as recommended by the EQUATOR
(Enhancing the QUAlity and Transparency Of health Research) network. ${ }^{12}$

For both surveys, no personal identifiers were linked to survey results, and the data were stored on the password-protected computer of the primary investigator (C.W.). An informed consent form was attached to the email invitations for the surveys, and a link to the form was also provided in the introduction page to each survey. No incentives were offered for completing either of the surveys.

The study was approved by the Hamilton Integrated Research Ethics Board.

\section{Survey of Ontario Hospital Pharmacists Study Design}

To determine the prevalence of burnout, a voluntary, cross-sectional open online survey was conducted using a convenience sample of Ontario hospital pharmacists. To recruit a broad and diverse geographic sample, an invitation to the survey was distributed to members of the Ontario Branch of the Canadian Society of Hospital Pharmacists via the branch e-Newsbrief, as well as to pharmacists at 33 hospital corporations representing more than 67 unique hospital sites across Ontario, through their staff pharmacist email distribution lists.

Before survey distribution, a pilot version was administered to 118 hospital pharmacists within a single hospital corporation (4 hospitals), to ensure that the questionnaire and consent forms were clearly understandable and appropriately worded to accurately investigate the intended research questions. All comments and feedback from the pilot respondents were taken into consideration, and the survey was modified accordingly. Responses from the pilot survey were also included in the province-wide data.

The pilot survey was administered in March 2019 and the province-wide survey in April and May 2019. For both surveys, an online survey platform, SurveyMonkey, was used to administer and collect responses through an automatic capture method. The questions were not randomized because the tool used for assessment of burnout, the Maslach Burnout Inventory (MBI), requires a standard order of questions. Adaptive questioning was used to minimize the complexity of the survey and to direct respondents to questions that were conditionally relevant according to their responses on other items. Respondents were not able to review or change their responses after proceeding to the next page of the survey.

All hospital pharmacists in Ontario were eligible to participate in the study. Pharmacy residents and students have different responsibilities and work environments than licensed pharmacists, with exposure to different stressors and risk factors. These groups were therefore deemed to represent a different population from pharmacists, and any responses from residents or students were excluded from the analysis. Respondents who did not complete the 
full MBI were also excluded from the analysis because the level of burnout cannot be assessed from incomplete MBI information.

\section{Survey Content}

The survey questionnaire comprised 2 sections: the MBI itself and questions about personal and career characteristics and professional satisfaction. In total, there were 45 questions. All of the quantitative survey questions were mandatory, with a "prefer not to answer" option for questions about personal and work characteristics.

The first section used the standardized MBI Human Services Survey for Medical Personnel, which has been validated with various health care practitioners. ${ }^{1,5}$ This inventory consists of 22 items that measure burnout in terms of emotional exhaustion, depersonalization, and personal accomplishment. Responses range from "never" (numeric value 0 ) to "every day" (6), according to the frequency at which the respondent experiences each item. Scores are tallied for each of the 3 components, and each score is assessed as high, moderate, or low, according to values validated in the MBI for health care professionals. ${ }^{1}$ Burnout was defined on the basis of previously defined threshold values for health care providers, either as an emotional exhaustion score of 27 or higher or a depersonalization score of 10 or higher. ${ }^{5}$

The second section of the survey comprised questions about personal and work characteristics, as well as questions about professional satisfaction. Respondents were asked to rate satisfaction with various areas of their career from 0 to 5 , where $0=$ very dissatisfied and $5=$ very satisfied. They were also asked to rate satisfaction with time spent in work-related activities or tasks from 0 to 2 , where $0=$ too little and $2=$ too much.

\section{Statistical Analysis}

Descriptive statistics (medians with interquartile ranges and counts with percentages) were used to summarize the survey responses and demographic characteristics of respondents. Those with scores suggestive of burnout were compared with those whose scores were not suggestive of burnout. Descriptive statistics were also used to characterize differences in demographics and professional satisfaction between these groups.

To examine the relationship between professional dissatisfaction and burnout, univariable logistic regression analysis was conducted. To adjust for confounding baseline variables (e.g., age, sex, years in practice, working full-time, and primary area of practice), multivariable analysis was used to determine factors independently associated with burnout. All analyses used 2-tailed statistical tests, with statistical significance defined by a threshold $p$ value of less than 0.05 . A variance inflation factor greater than 10 was used as the threshold for determining the presence of significant multicollinearity. ${ }^{13}$
SPSS software (SPSS Statistics for Windows, version 25.0, IBM Corporation) was used to conduct the statistical analyses and logistic regression analyses.

The survey also included 3 qualitative questions. Those who felt burned out, based on their own self-assessment, were asked, "What do you feel are the biggest contributors to your feelings of burnout?" and "What do you feel is the most helpful to relieve and/or cope with your feelings of burnout?" Those who did not feel burned out were asked, "What do you feel has been most helpful to you in preventing burnout?" The responses to qualitative questions were analyzed using thematic content analysis, in which responses were grouped according to recurring themes, such as spending time with family or exercising.

\section{Survey of Canadian Schools of Pharmacy}

The second survey was a voluntary, self-administered, closed online survey of leadership faculty at each of the pharmacy schools in Canada. Potential respondents representing each school were chosen on the basis of job title (either the dean of pharmacy or a relevant faculty representative responsible for curricular development). The survey consisted of 4 questions about the current availability of and interest in incorporating preventive skill-building strategies against burnout syndrome. Descriptive statistics were used to summarize the survey responses.

\section{RESULTS}

\section{Survey of Ontario Hospital Pharmacists}

Of the 2475 hospital pharmacists licensed in Ontario at the time of the survey, ${ }^{14} 388$ completed at least a portion of the survey. Of these, 118 were excluded: 19 who were not staff hospital pharmacists (but rather were pharmacy students or residents) and 99 who quit the survey before completing the MBI. Therefore, the final analysis included 270 respondents who met the eligibility criteria, which corresponds to a response rate of $11 \%$.

In the included cohort, most of the respondents were women (77\% [195/252]), nearly half were between the ages of 35 and 44 years (43\% [109/253]), and most were practising full-time (90\% [227/252]). Median time in practice was 11 years, with a large proportion of respondents practising in the acute care setting (39\% [96/246]). Full details of respondents' demographic and career-related characteristics are shown in Table 1. There were no statistically significant differences in any of the measured baseline characteristics between respondents with and without burnout (as determined from MBI scores).

The overall burnout rate was $61.1 \%$ (95\% confidence interval [CI] $55.5 \%-66.8 \% ; n=165)$. This outcome was driven by the large proportions of respondents who had high emotional exhaustion $(n=144,53 \%)$ and high depersonalization $(n=114,42 \%)$ (Table 2$)$. In the univariable regression 


\begin{tabular}{|c|c|c|c|c|}
\hline \multirow[b]{2}{*}{ Characteristic } & \multicolumn{3}{|c|}{ Group $^{\mathrm{a}}$; No. $(\%)$ of Respondents ${ }^{\mathrm{b}}$} & \multirow[b]{2}{*}{$p$ Value $^{c}$} \\
\hline & Not Burned Out $(n=105)$ & Burned Out $(n=165)$ & All $(n=270)$ & \\
\hline Age group (years) & $n=98$ & $n=155$ & $n=253$ & 0.96 \\
\hline $18-24$ & (1) & $(2)$ & $(2)$ & \\
\hline $25-34$ & $6 \quad(6)$ & (6) & $15 \quad(6)$ & \\
\hline $35-44$ & $44 \quad(45)$ & $65 \quad(42)$ & $109 \quad(43)$ & \\
\hline $45-54$ & $26 \quad(27)$ & $47 \quad(30)$ & $73 \quad(29)$ & \\
\hline $55-64$ & $13 \quad(13)$ & $18 \quad(12)$ & $31 \quad(12)$ & \\
\hline Sex & $n=98$ & $n=154$ & $n=252$ & 0.57 \\
\hline Female & $74 \quad(76)$ & $121 \quad(79)$ & $195 \quad(77)$ & \\
\hline Time in practice (years) (median and IQR) & $10(5-20)$ & $11(6-20)$ & $11(5-20)$ & 0.94 \\
\hline Work hours & $n=99$ & $n=153$ & $n=252$ & 0.36 \\
\hline Full-time & $88 \quad(89)$ & $139 \quad(91)$ & $227 \quad(90)$ & \\
\hline Primary area of practice & $n=96$ & $n=150$ & $n=246$ & 0.30 \\
\hline Acute care & $40 \quad(42)$ & $56 \quad(37)$ & $96 \quad$ (39) & \\
\hline Critical care & $14 \quad(15)$ & $15 \quad(10)$ & $29 \quad(12)$ & \\
\hline Rehabilitation or long-term care & (3) & $17 \quad(11)$ & (8) & \\
\hline Oncology & $11 \quad(11)$ & $(15)$ & $34 \quad(14)$ & \\
\hline Management & (3) & (5) & (4) & \\
\hline Outpatient/ambulatory & $14 \quad(15)$ & $15 \quad(10)$ & (12) & \\
\hline$\geq 3$ areas & (5) & (6) & (6) & \\
\hline Other & (6) & (5) & (6) & \\
\hline
\end{tabular}

$\mathrm{IQR}=$ interquartile range.

aBurnout was assessed through analysis of responses to the Maslach Burnout Inventory.

bexcept where indicated otherwise. Data were missing for some respondents for each variable; as such, the column heading shows the total number in each group and entries below indicate the number of respondents by variable.

'Comparison between respondents without and with burnout.

analysis, respondents who rated themselves as being very or somewhat dissatisfied with most of the work-related characteristics were also more likely to have burnout (Table 3). The only 2 characteristics not associated with burnout were dissatisfaction with time spent in clinical duties and dissatisfaction with time spent with students or teaching.

After adjustment for age, sex, years in practice, working full-time, and primary area of practice, multivariable logistic regression showed 2 factors to be independently associated with burnout: dissatisfaction with work-life balance (odds ratio $[\mathrm{OR}] 2.62,95 \% \mathrm{CI} 1.33-5.18, p=0.005)$ and feeling that contributions were not appreciated (OR 2.60, 95\% CI 1.17$5.78, p=0.019)$. No significant multicollinearity was detected between independent variables used in the analysis.

In the qualitative portion of the survey, respondents were asked to identify the perceived contributors to their burnout. The most prominent themes to emerge were perceived high or unmanageable workload, lack of worklife balance, and lack of appreciation by colleagues and management. When respondents were asked about factors protective against burnout, the most common responses were taking time away from work, social interactions, and activities or exercise outside of work (Table 4).
When respondents were asked if they subjectively felt burned out, 23\% (36/158) of those identified objectively as having burnout (based on the MBI) answered "No".

TABLE 2. Assessment of Burnout According to Maslach Burnout Inventory

\begin{tabular}{lcrc} 
Aspect of Burnout & $\begin{array}{c}\text { Median Score } \\
(\text { IQR) }\end{array}$ & $\begin{array}{c}\text { No. (\%) of } \\
\text { Respondents } \\
(\boldsymbol{n}=\mathbf{2 7 0})\end{array}$ \\
\hline Emotional exhaustion & $28(20-36)$ & 59 & $(22)$ \\
$\quad$ Low score $(\leq 18)$ & 67 & $(25)$ \\
Moderate score & & 144 & $(53)$ \\
High score $(\geq 27)$ & & & \\
Depersonalization & $8(4-15)$ & 91 & $(34)$ \\
Low score $(\leq 5)$ & & 65 & $(24)$ \\
Moderate score & & 114 & $(42)$ \\
High score $(\geq 10)$ & & & \\
Personal accomplishment & $38(31-42)$ & 81 & $(30)$ \\
Low score $(\leq 33)$ & & 80 & $(30)$ \\
Moderate score & & 109 & $(40)$ \\
High score $(\geq 40)$ & & & \\
\hline
\end{tabular}

$\mathrm{IQR}=$ interquartile range. 
This finding suggests that about 1 of every 4 respondents with burnout was not self-aware. Twelve percent (31/258) of respondents had exposure to some type of burnoutprevention training in their career, but less than $1 \%(2 / 258)$ had received training at the undergraduate level.

\section{Survey of Canadian Schools of Pharmacy}

The survey of Canadian pharmacy schools had a $100 \%$ response rate. Nine (90\%) of the 10 schools did not currently have burnout-prevention curricula, but 8 (80\%) expressed interest in incorporating such programs. Only one Canadian school reported current provision of burnout-prevention training. The training is limited and consists of a conference at the beginning of the pharmacy program, which includes a mindfulness workshop and a presentation by a psychologist.

\section{DISCUSSION}

This survey of hospital pharmacists in Ontario, Canada, found a burnout rate of $61.1 \%$. This suggests that the burnout rate for pharmacists is as concerning as those previously

TABLE 3. Univariable Regression Analysis for Relation between Professional Dissatisfaction and Burnout

\begin{tabular}{lccc} 
Dissatisfaction Variable $^{\mathrm{a}}$ & \multicolumn{2}{c}{ Odds Ratio (95\% Cl) } & $\boldsymbol{p}$ Value \\
\hline Overall career & 6.93 & $(2.38-20.15)$ & $<0.001$ \\
\hline Work-life balance & 3.87 & $(2.20-6.80)$ & $<0.001$ \\
\hline Interactions with RPh colleagues & 4.73 & $(2.03-11.01)$ & $<0.001$ \\
\hline $\begin{array}{l}\text { Interactions with non-RPh } \\
\text { colleagues }\end{array}$ & 5.88 & $(1.72-20.08)$ & 0.005 \\
\hline Intellectual challenge at work & 3.13 & $(1.14-8.54)$ & 0.026 \\
\hline $\begin{array}{l}\text { Feeling contributions are } \\
\text { appreciated }\end{array}$ & 4.81 & $(2.63-8.82)$ & $<0.001$ \\
\hline Time for professional growth & 2.28 & $(1.20-4.32)$ & 0.012 \\
\hline Time spent in clinical duties & 1.60 & $(0.96-2.65)$ & 0.07 \\
\hline Time for administrative tasks & 1.68 & $(1.01-2.80)$ & 0.047 \\
\hline Time spent with students/teaching & 1.66 & $(0.99-2.78)$ & 0.06 \\
\hline
\end{tabular}

$\mathrm{Cl}=$ confidence interval, $\mathrm{RPh}=$ registered pharmacist.

aRated as very or somewhat dissatisfied. reported for physicians (30\%-54\%) and nurses (35\%-40\%) in both Canada and the United States ${ }^{3,15-17}$ (see Box 1). In the current survey, higher burnout rates were independently associated with a reduced work-life balance and decreased sense of worth in the workplace. These results correlated strongly with the qualitative responses, where the biggest contributors to pharmacist burnout were a lack of appreciation by colleagues and management and a lack of work-life balance.

The subscales for emotional exhaustion, depersonalization, and decreased personal accomplishment all had a substantial proportion of respondents scoring in the "high" range (Table 2). These results suggest that all of the subscales are contributing to burnout and that all 3 domains need to be addressed to combat burnout. There were also a large number of respondents who scored in the "moderate" range of the subscales, suggesting that even though they did not meet the predefined cut-offs for burnout, these respondents were likely at risk of developing burnout.

This high burnout rate is concerning. It is similar to that found by a pilot survey of US clinical hospital pharmacists, in which the burnout rate was $61.2 \% .^{5}$ That US study also found an association between burnout and the feeling that contributions were underappreciated. Additional factors associated with burnout in that earlier study were inadequate administration and teaching time, uncertainty about health care reform, too many nonclinical duties, and "difficult" pharmacist colleagues. With the exception of uncertainty about health care reform, which we did not consider, these same factors also trended toward an association with burnout in our Canadian survey. However, we were unable to confirm whether these are important factors for Canadian pharmacists. This is likely because of a lack of statistical power.

The lack of burnout self-awareness demonstrated in this study is particularly concerning. The lack of self-awareness may stem from a lack of education regarding burnout or from a work culture where stress and busy-ness are accepted as normal. Regardless, such a gap in self-awareness is problematic. Affected pharmacists may continue to work through any feelings of emotional exhaustion and depersonalization. Over time, fatigue may accumulate and ultimately impair the quality of patient care. Other health care professional associations have recognized similar

\section{TABLE 4. Self-Reported Influences on Burnout: Prominent Themes in Qualitative Questions}

\section{Protective Factors against Burnout}

Time away from work (e.g., vacation, working part-time, taking full lunch hour)

Social interactions (e.g., with colleagues, with family and friends outside of work)

Activities/exercise outside of work

\section{Contributors to Burnout}

Workload too high (e.g., understaffed, working through lunch, working late to keep up)

Lack of work-life balance (e.g., energy to play with kids after work)

Lack of appreciation by colleagues and management 


\section{BOX 1. Key Points}

Burnout among hospital pharmacists is high (61\%) and comparable to burnout rates among physicians and nurses.

There is a gap in self-awareness among pharmacists who are burned out, an alarming phenomenon that can perpetuate burnout and could lead to suboptimal patient care.

Preventive burnout curricula are not widely implemented in pharmacy schools, but there exists an opportunity to develop such education to prepare students for the occurrence of burnout once they are in the workforce.

gaps in burnout awareness. For example, the Accreditation Council for Graduate Medical Education increased its efforts to support medical trainees and teachers in the United States to recognize the signs and symptoms of burnout; it also provided access to support and coaching in techniques to combat burnout. ${ }^{18}$ In turn, pharmacists may also benefit from early education about burnout and the strategies available for early implementation against burnout in the workforce.

The data gathered in this study suggest 3 different platforms from which we can target burnout reduction among pharmacists: individual, system and management, and educational.

At the individual level, respondents identified several contributors to burnout, such as high workload, as well as protective factors, such as extracurricular hobbies and support from family and friends. A recurrent theme was to "leave work at work". Certainly, many options are available for following this advice, such as "taking vacation" or "exercising". Notably, if employees are to implement these strategies, they will need support from management. Placing the responsibility for preventing burnout solely on the individual might lead employees to seek out solutions that could be detrimental to the organization, such as reducing professional work effort. ${ }^{19}$ Furthermore, although it makes sense to institute mindfulness training or create wellness programs to reduce employees' stress, it would be a mistake to overlook the system-level issues that intensify that stress. ${ }^{20}$

In the health care system at large, burnout among health care providers is associated with decreased quality of care and patient safety. ${ }^{2,3}$ Health care providers may become disengaged, less committed, and possibly cynical. These attitudes may present challenges for organizational leaders as staff members, including pharmacists, reduce their collaborative efforts with colleagues and management, leading to suboptimal functioning of the health care system. Typically, accountability for addressing burnout and instituting change is placed on the individual. However, as with any systems-level thinking, tackling burnout should be a shared responsibility. The potential impact of management-led initiatives should not be underestimated. In a systematic review of burnout interventions among US physicians, Dyrbye and others ${ }^{21}$ found that both individual and institutional interventions were needed to reduce burnout.

In our survey, pharmacists reported feeling underappreciated by their pharmacist colleagues, management, and colleagues from other professions. They also felt underacknowledged for working extra hours (e.g., working overtime, working through lunch) and for the high-quality patient care that they provide. Some of these factors can be addressed at the management level, where institutional initiatives to promote pharmacist achievements could help tackle such sentiments. Opportunities such as recognition during daily team huddles (i.e., brief meetings of health care staff that help to foster connections and alignment among staff through sharing of organizational goals, metrics, and individual achievements) or continuous quality improvement meetings represent "low-hanging fruit" that may be easier to incorporate than certain other initiatives. In a study of 14 hospitals with established recognition programs and 10 hospitals without such programs, meaningful recognition was found to be a significant predictor of decreased burnout among nurses. ${ }^{22}$

At the undergraduate level, education about burnout recognition and prevention strategies has commonly been implemented in faculties of nursing and medicine. ${ }^{6-11}$ Among medical students, resiliency training programs, compassion fatigue programs, and self-relaxation programs have all been effective in improving burnout scores. ${ }^{6-8}$ There is also a significant body of literature describing successful interventions to prevent burnout among nursing students. Strategies with some evidence for efficacy include acceptance and commitment training, a music integrative program, and a psychosocial training program. ${ }^{9-11}$ Given this existing body of research, burnout education for pharmacy students could help them to identify symptoms and seek help earlier when experiencing symptoms of burnout in their professional careers. Currently, 9 of the 10 pharmacy schools in Canada do not offer any type of burnoutprevention education, but 8 out of these 9 schools would be open to including such content in the curriculum. Notably, McQuade and others ${ }^{23}$ identified an increase in emotional exhaustion scores among US pharmacists before and after the year 2000, which correlated with a rise in clinical duties and responsibilities. It is reasonable to expect that with changes and expansion in pharmacists' professional scope will come a need to evaluate and update the means by which pharmacists are equipped with skills to combat burnout. Similar to curricula for other health care professions, the undergraduate pharmacy school curriculum may be an appropriate point to introduce strategies for recognition and prevention of burnout, in anticipation of burnout occurring once students graduate and join the workforce.

To the authors' knowledge, this is the first study to measure burnout and characterize associated risk factors in 
a population of Canadian pharmacists. The survey reached a broad distribution of pharmacists and practice settings across Ontario, including 33 hospital corporations representing 67 hospital sites, CSHP Ontario Branch members, and both community and academic hospitals. The response rate was good and comparable to other similar studies involving health care professions. ${ }^{3}$ To our knowledge, this was also the first study that surveyed faculties of pharmacy about burnout curricula to better understand the baseline level of relevant education. The validity of our results is strengthened by comparable burnout rates among US hospital pharmacists $(61.1 \%$ versus $61.2 \%) .^{5}$

This study had some limitations. Because the survey was voluntary, there was a risk of selection bias. It is possible that those who participated in the study were inherently different from those who did not participate. For example, pharmacists who were feeling burned out might have been more inclined to complete the survey because they identified with the survey topic. Alternatively, pharmacists who were feeling burned out might have been less inclined to spend their time on a voluntary survey with no incentives for participation. The prevalence of burnout may therefore be under- or over-represented by our findings.

The results of this study are also subject to the inherent limitations of the MBI. Although the MBI is the most widely used measure of burnout, with well-established reliability and validity, it treats burnout as a 1-dimensional, dichotomous state based on threshold cut-off scores within individual categories (e.g., emotional exhaustion). For some individuals, however, burnout may exist on a multifactorial continuum. ${ }^{24}$ In addition, there may be individuals with burnout scores just below the cut-offs (i.e., in the moderate range) who may actually be experiencing burnout, but they would not be identified with the MBI. Although this study used the cut-off values most commonly used in the literature to determine burnout rates, some previous studies may have used other cut-offs, which may make comparisons more difficult.

Although the need for preventive strategies has been identified, as well as an interest in covering this topic in the undergraduate pharmacy curricula, further research is needed to determine which types of interventions will be most effective for both pharmacists and pharmacy students and what type of curricular interventions will be successful in the long-term, once students have graduated.

\section{CONCLUSION}

The rate of burnout among Canadian hospital pharmacists is high and is similar to that among US health-system pharmacists. Preventive action is needed across North America. Opportunities exist to both improve pharmacists' resilience at the undergraduate level and reduce institutional stressors in the workplace.

\section{References}

1. Maslach C, Leiter M. Maslach burnout inventory manual. 4th ed. Consulting Psychologists Press; 1996.

2. Hall L, Johnson J, Watt I, Tsipa A, O’Connor D. Healthcare staff wellbeing, burnout, and patient safety: a systematic review. PLoS One. 2016;11(7):e0159015.

3. CMA national physician health survey: a national snapshot. Canadian Medical Association; 2018 Oct [cited 2019 Jul 4]. Available from: https://www.cma.ca/sites/default/files/2018-11/nph-survey-e.pdf

4. Powell A. Study: doctor burnout costs health care system $\$ 4.6$ billion a year. Harvard Gazette. 2019 Jul 12 [cited 2019 Aug 20]. Available from: https://news.harvard.edu/gazette/story/2019/07/doctor-burnoutcosts-health-care-system-4-6-billion-a-year-harvard-study-says/

5. Jones GM, Roe NA, Louden L, Tubbs CR. Factors associated with burnout among US hospital clinical pharmacy practitioners: results of a nationwide pilot survey. Hosp Pharm. 2017;52(11):742-51.

6. Wild K, Scholz M, Ropohl A, Bräuer L, Paulsen F, Burger PHM. Strategies against burnout and anxiety in medical education - implementation and evaluation of a new course on relaxation techniques (Relacs) for medical students. PLoS One. 2014;9(12):e114967.

7. Peng L, Li M, Zuo X, Miao Y, Chen L, Yu Y, et al. Application of the Pennsylvania resilience training program on medical students. Personal Individ Differ. 2014;61-62:47-51.

8. Tucker T, Bouvette M, Daly S, Grassau P. Finding the sweet spot: developing, implementing and evaluating a burn out and compassion fatigue intervention for third year medical trainees. Eval Program Plann. 2017;65:106-12.

9. Frögeli E, Djordjevic A, Rudman A, Livheim F, Gustavsson P. A randomized controlled pilot trial of acceptance and commitment training (ACT) for preventing stress-related ill health among future nurses. Anxiety Stress Coping. 2015;29(2):202-18.

10. Bittman BB, Snyder C, Bruhn KT, Liebfreid F, Stevens CK, Westengard J, et al. Recreational music-making: an integrative group intervention for reducing burnout and improving mood states in first year associate degree nursing students: insights and economic impact. Int J Nurs Educ Scholarsh. 2004;1:Article 12.

11. Škodová Z, Lajčiaková P. Impact of psychosocial training on burnout, engagement, and resilience among students. Cent Eur J Nurs Midw. 2015;6(3):313-9.

12. Eysenback G. Improving the quality of web surveys: the checklist for reporting results of internet e-surveys (CHERRIES). J Med Internet Res. 2004;6(3):e34.

13. Kutner M, Nachtsheim C, Neter J, Li W. Applied linear statistical models. 4th ed. McGraw-Hill/Irwin; 2004.

14. National statistics. National Association of Pharmacy Regulatory Authorities; 2019 [cited 2019 Jul 22]. Available from: https://napra.ca/ national-statistics

15. Hildebrandt A. Nearly $25 \%$ of Canadian nurses wouldn't recommend their hospital. Burnout plagues about $40 \%$ of respondents, CBC survey suggests. CBC News. 2013 [cited 2019 Aug 13]. Available from: www.cbc.ca/beta/news/health/nearly-25-of-canadian-nures-wouldnt-recommend-their-hospital-1.1304601

16. Berg S. Physician burnout: which medical specialties feel the most stress. American Medical Association; 2020 Jan 21 [cited 2020 Apr 10] Available from: https://www.ama-assn.org/practice-management/ physician-health/physician-burnout-which-medical-specialties-feelmost-stress

17. Dyrbye LN, Shanafelt TD, Johnson PO, Johnson LA, Satele D, West CP. A cross-sectional study exploring the relationship between burnout, absenteeism, and job performance among American nurses. BMC Nurs. 2019;18:Article 57

18. Improving physician well-being, restoring meaning in medicine [webpage]. Accreditation Council for Graduate Medical Education; [cited 2019 Dec 12]. Available from: https://www.acgme.org/What-We-Do/ Initiatives/Physician-Well-Being

19. Shanafelt TD, Noseworthy JH. Executive leadership and physician 
well-being: nine organizational strategies to promote engagement and reduce burnout. Mayo Clin Proc. 2017;92(1):129-46.

20. Shannon DW. Individual vs. system fixes: does it need to be either/or? Shannon Healthcare Communications; 2017 Oct 16 [cited 2020 Feb 10]. Available from: https://dianeshannon.com/ individual-vs-system-fixes-does-it-need-to-be-either-or/

21. Dyrbye LN, Erwin PJ, Shanafelt TD, West CP. Interventions to prevent and reduce physician burnout: a systematic review and meta-analysis. Lancet. 2016;388(10057):2272-81.

22. Kelly L, Lefton C. Effect of meaningful recognition on critical care nurses' compassion fatigue. Am J Crit Care. 2017;26(6):438-44.

23. McQuade BM, Reed BN, DiDomenico RJ, Baker WL, Shipper AG, Jarrett JB. Feeling the burn? A systematic review of burnout in pharmacists. J Am Coll Clin Pharm. 2020;3(3):663-75.

24. Doulougeri K, Georganta K, Montgomery A. "Diagnosing" burnout among healthcare professionals: can we find consensus? Cogent Med. 2016;3(1). DOI: 10.1080/2331205X.2016.1237605
Colby Weichel, BSc, PharmD, is with the Department of Pharmacy, Toronto East Health Network, Toronto, Ontario.

Joan S Lee, BScPhm, ACPR, is with the Department of Pharmacy, Hamilton Health Sciences, Hamilton, Ontario.

Justin Y Lee, BScPhm, ACPR, MD, FRCPC, is with the Department of Medicine, McMaster University, Hamilton, Ontario.

Competing interests: None declared.

Address correspondence to:

Dr Colby Weichel

Department of Pharmacy, Toronto East Health Network

825 Coxwell Avenue

Toronto ON M4C 3E7

email: colby.weichel@tehn.ca

Funding: This study was funded by a Canadian Institutes of Health Research Post-Doctoral Fellowship Award research allowance, as well as a Professional Salary Award held by the program coordinator of the Hamilton Health Sciences pharmacy residency program.

Acknowledgement: The authors acknowledge Mark Duffett, PhD, RPh, for assistance with funding, as well as project support.

\section{BEST...is better}

\section{One resource for all types of compounding by pharmacies}

\section{WHAT'S INSIDE?}

- Information for pharmacists, pharmacy technicians, planners, architects, engineers-and others who are involved in decisions or activities that affect compounding

- Guidelines for aseptic compounding, non-aseptic compounding, and compounding which involves hazardous drugs-including radiopharmaceuticals

- Best and leading guidelines on topics such as training, planning and designing the physical environment, developing an air quality strategy, cleaning and decontaminating areas, monitoring the environment, garbing and hand hygiene, developing compounding procedures, documenting, and much more-all in only 230 pages
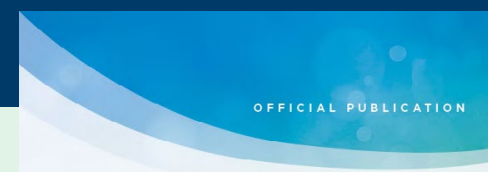

Compounding: Guidelines for Pharmacies

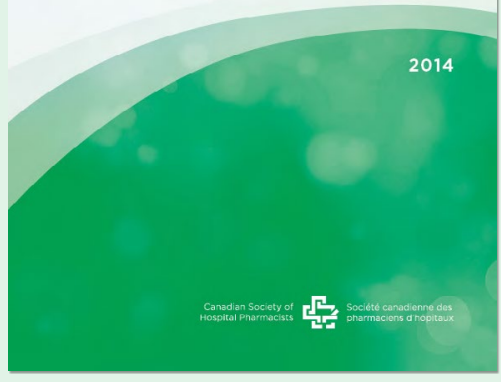

Learn what best looks like: add this publication to your library!
HAVE A SNEAK PEEK OR ORDER AT: https://www.cshp.ca/site/res/other/guidelines?nav=resources CSHP MEMBERS PAY A DISCOUNTED PRICE
Canadian Society of Hospital Pharmacists
Société canadienne des pharmaciens d'hôpitaux 